\title{
Nano-tip Electron Gun for the Scanning Electron Microscope
}

\author{
A. E. Vladár, Z. Radi, M. T. Postek and D. C. Joy ${ }^{1}$ \\ National Institute of Standards and Technology*, Gaithersburg, MD 20899 M/s. 8212 \\ ${ }^{1}$ University of Tennessee
}

Experimental nano-tips have shown significant improvements in the resolution performance of a cold field emission scanning electron microscope. Nano-tip electron sources are very sharp electron emitter tips used as a replacement for the conventional tungsten field emission (FE) electron sources. Nano-tips offer higher brightness and smaller electron source size. An electron microscope equipped with nano-tip electron gun can provide images with higher spatial resolution and with better signalto-noise ratio. This could present a considerable advantage over the current scanning electron microscope (SEM) electron gun technology if the tips are sufficiently long-lasting and stable for practical use. In this study, an older field emission critical dimension (CD) SEM (vintage1998 Hitachi S-6000**) was used as an experimental test platform. Substitution of nano-tips for the regular cathodes required modification of the electron gun circuitry and preparation of nano-tips that properly fit the electron gun assembly. In addition, this work contains the results of the modeling and theoretical calculation of the electron gun performance for regular and nano-tips, the preparation of the SEM including the design and assembly of a measuring system for essential instrument parameters, design and modification of the electron gun control electronics, development of a procedure for tip exchange, and tests of regular emitter, sharp emitter and nano-tips. Nano-tip fabrication and characterization procedures were also developed. Using a "sharp" tip as an intermediate to the nano-tip clearly demonstrated an improvement in the resolution performance of the test SEM, which has a specification of $15 \mathrm{~nm}$ attainable resolution. (Figure 1) This and the results of the theoretical assessment gave support for the installation of the nano-tips as the next step and pointed to potentially even better performance. Images taken with experimental nano-tips showed a minimum two-fold improvement in resolution performance than the specification of the test SEM (Figure 2). The stability of the nano-tip electron gun was excellent, the tip stayed useful for highresolution imaging for several hours during many days of tests. The tip lifetime was found to be several months in light use. This paper summarizes the current state of the work and points to future possibilities that will open when electron guns can be designed to fully take the advantage of the nano-tip electron emitters.

Based on the results it appears feasible that nano-tip gun technology could replace the standard electron source and thus provide increased instrument performance. The result of this work clearly demonstrated that the improvements predicted by the theoretical calculations can actually be achieved in practice. The lifetime and resolution of the nano-tip gun were surprisingly good, which opens the possibility for the development of a new higher-resolution electron gun technology. Continued work is ongoing and it is expected that the next step for the nano-tip will be a test in a more modern cold field emission instrument to determine how far the performance can be pushed. 

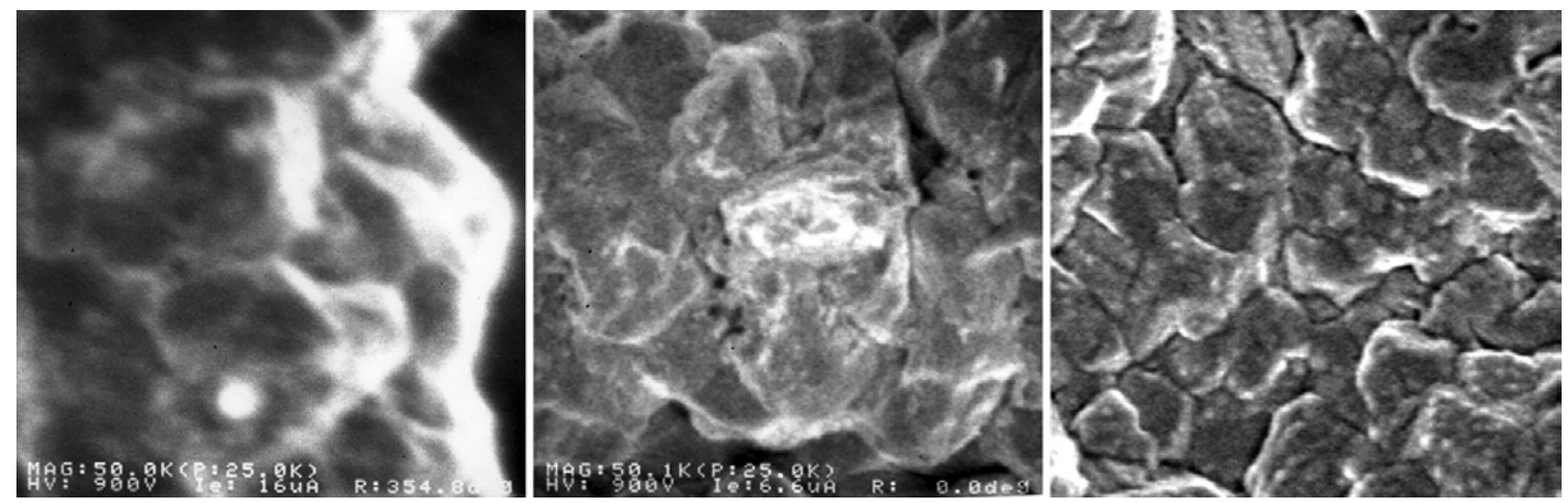

Figure 1. Copper grid sample images taken with the original tip (left), sharp tip (middle) and nano-tip (right). The field-of-view is $3 \mu \mathrm{m}$ and the accelerating voltage is $900 \mathrm{~V}$, for all images. The emission currents are $16 \mu \mathrm{A}$ (left) $6.6 \mu \mathrm{A}$ (middle) and $2 \mu \mathrm{A}$ right images.

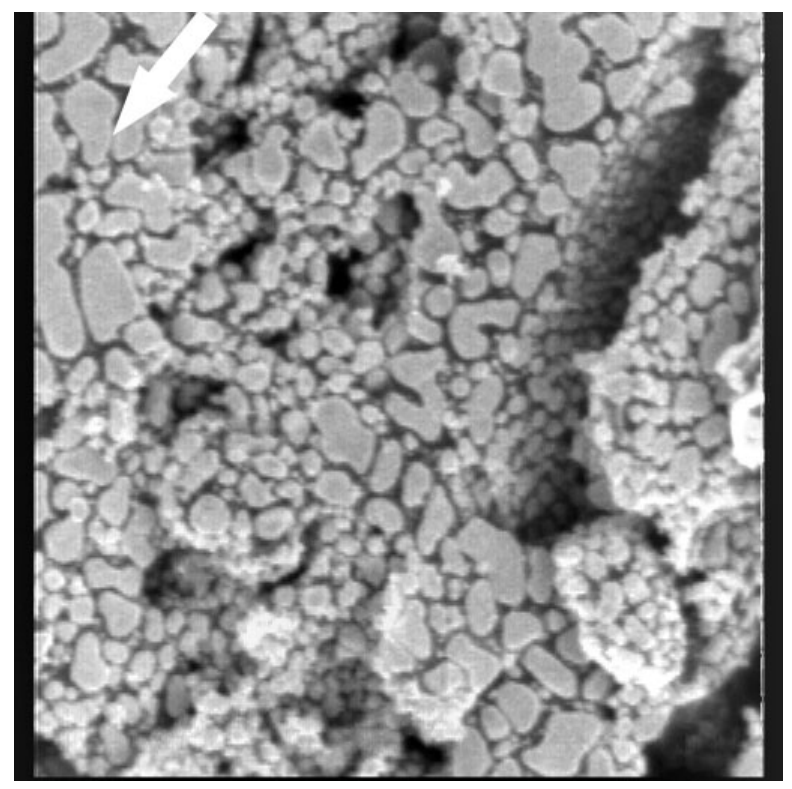

Figure 2. Image taken on a gold-on-carbon resolution sample. $900 \mathrm{~V}$ accelerating voltage, $2 \mu \mathrm{A}$ emission current. The gap marked with the arrow is approximately $6 \mathrm{~nm}$ wide. The field-of-view is $1.75 \mu \mathrm{m}$.

* Contribution of the National Institute of Standards and Technology, not subject to copyright.

** Certain commercial equipment is identified in this report to adequately describe the experimental procedure. Such identification does not imply recommendation or endorsement by the National Institute of Standards and Technology, nor does it imply that the equipment identified is necessarily the best available for the purpose. 